\title{
RESPOSTAS DOS PADRÕES DE SEDIMENTAÇÃO E HIPERSALINIDADE NA COBERTURA VEGETAL DE PLANÍCIE ESTUARINA SOB INFLUÊNCIA DA SEMIARIDEZ
}

\author{
David Hélio Miranda de Medeiros ${ }^{1}$ \\ Andrea Almeida Cavalcante ${ }^{2}$ \\ Lidriana de Souza Pinheiro ${ }^{3}$
}

\begin{abstract}
Resumo: Esta pesquisa analisa a influência das variações espaciais da salinidade intersticial e granulometria dos sedimentos na cobertura vegetal do estuário do Rio Apodi-Mossoró (RN). Foram distribuídos 10 pontos amostrais para identificar a salinidade e granulometria dos sedimentos; os mapas temáticos da cobertura vegetal foram elaborados através de técnicas de processamento de imagens LandSat 8. O trecho da foz (pontos 1-2) apresentou domínio das frações arenosas; nos demais pontos predominam sedimentos siltosos. Da foz ao ponto 5 , de salinidade < $50 \%$, estão os trechos mais extensos de manguezal. Todavia, os pontos 3, 6, 7, 8, 9 e 10 apresentaram elevada salinidade, com cobertura vegetal típicas de apicuns/salgados e solos expostos. Portanto, os depósitos de finos favorecem a retenção de sais, contribuindo para hipersalinidade, que se torna principal fator limitante ao desenvolvimento do manguezal. Palavras-chave: Estuário; Semiárido; Hipersalinidade; Cobertura Vegetal
\end{abstract}

\section{RESPONSES OF SEDIMENTATION AND HYPERSALINITY STANDARDS IN VEGETATION COVERAGE OF ESTUARINE PLAIN THE INFLUENCE OF A SEMIARID CLIMATE REGIME}

\begin{abstract}
This research analyzes interstitial salinity space variations and sediment granulometry influence over Apodi-Mossoró River cover of the estuary. Ten sampling points were allocated to identfify salinity and granulometry of sediments; thematic maps of the vegetation cover were elaboratede through LandSat 8 image techniques. The stretch of the mouth (points 1-2) showed domunance of sandy fractions/ in other areas siltous sediments are predominant. From the mouth to point 5 , wtih salinity $<50 \%$, mangrove more extensive stretches can be found. However, points 3, 6, 7, 8, 9 and 10 presented high salinity levels, with salt marsh vegetation cover and exposed soils. Therefore, fine deposits favors the retention of salts, contributing to hypersalinity, which becomes the main limiting factor for mangrove development.
\end{abstract}

Keywords: Estuary; Semiarid; Hypersalinity; Vegetal Cover

\footnotetext{
${ }^{1}$ Programa de Pós-Graduação em Ciências Marinhas Tropicais - PPGCMT. Universidade Federal do Ceará. Email: davidgeo.ambiental@yahoo.com.br

${ }^{2}$ Prof ${ }^{a}$. Dra. do Departamento de Geografia da Faculdade Dom Aureliano Matos - Universidade Estadual do Ceará. Prof a . Permanente do Programa de Pós-Graduação em Geografia da Universidade Estadual do Ceará. Email: andrea.cavalcante@uece.br

${ }^{3}$ Prof $^{\mathrm{a}}$. do Instituto de Ciências do Mar da Universidade Federal do Ceará. Prof ${ }^{\mathrm{a}}$. Permanente do Programa de Ciências Marinhas Tropicais da Universidade Federal do Ceará. Prof ${ }^{a}$. Permanente do Programa de Pós- 


\section{RESPUESTAS DE LOS ESTÁNDARES DE SEDIMENTACIÓN Y HIPERSALINIDAD EN LA COBERTURA VEGETAL DE LLANURA ESTUARINA BAJO INFLUENCIA DE SEMIARIDEZ}

Resumen: Esta investigación analiza la influencia de las variaciones espaciales de la salinidad intersticial y granulometría de los sedimentos en la cobertura vegetal del estuario del Río Apodi-Mossoró (RN). Se distribuyeron 10 puntos de muestreo para identificar la salinidad y granulometría de los sedimentos; los mapas temáticos de la cobertura vegetal fueron elaborados por técnicas de procesamiento de imágenes LandSat 8. El tramo de la desembocadura (puntos 1-2) presentó dominio de las fracciones arenosas; en los demás puntos predominan sedimentos siltosos. De la desembocadura al punto 5 , de salinidad $<50$ \%o, están los tramos más extensos de manglares. Sin embargo, los puntos 3, 6, 7, 8, 9 y 10 presentaron una elevada salinidad, con cobertura vegetal de salt flats y suelos expuestos. Por lo tanto, los depósitos de finos favorecen la retención de sales, contribuyendo a la hipersalinidad, que se convierte en principal factor limitante al desarrollo del manglar.

Palabras clave: Estuario; Semiárido; Hipersalidad; Cobertura Vegetal

\section{INTRODUÇÃO}

O litoral semiárido do Nordeste brasileiro corresponde ao trecho entre os Estados do Piauí, Ceará e toda extensão setentrional do Rio Grande do Norte (IBGE, 2007). As condições climáticas apresentam taxas de evaporação e evapotranspiração maiores do que as precipitações, determinando baixos influxos de água nos estuários (RAMOS E SILVA, 2004).

Como consequência, muitos estuários situados no semiárido são classificados, de acordo com o balanço hídrico e salinidade das águas, como "estuários negativos e/ou hipersalinos" (MIRANDA et al., 2012; MEDEIROS, 2016). Nos períodos de estio, geralmente entre os meses de junho a dezembro, as planícies estuarinas são inundadas apenas nas marés de sizígia, promovendo o gradativo aumento da salinidade (COSTA et al., 2015).

No litoral do RN, região que produz mais de $95 \%$ do sal marinho produzido no Brasil (COSTA et al., 2015), nas áreas de várzeas e planícies de inundação, os solos são constituídos por sedimentos argilo-arenosos não consolidados. No período de estiagem apresentam crostas superficiais de sais cristalizados formando extensas planícies hipersalinas ("salt flats") (SCHAEFFER-NOVELLI, 2005; MENDES et al., 2008). A presença dos sedimentos de granulometria fina, a exemplo das argilas e siltes, no solo pode implicar na maior retenção de água superficial e sais minerais (MORAIS; PINHEIRO, 2005).

As florestas de mangue ocorrem numa grande variedade de tipos estruturais, com diferentes composições específicas e estados de diversidade (SCHAEFFER-NOVELLI et al., 2000). Costa et al. (2014) estudando o estuário do Rio Apodi-Mossoró, observaram uma zonação da vegetação de manguezal, caracterizados por bosques mistos próximo à foz, 
compostos por quatro espécies de mangue (Avicennia germinans, Avicennia schaueriana, Laguncularia racemosa e Rhizophora mangle), que em estuário acima, são substituídos por agrupamentos monoespecíficos e, as vezes, mistos de A. schaueriana e L. racemosa para, por fim, serem encontrados grupamentos de plantas quase exclusivas de A. germinans na porção mais interior do estuário.

A salinidade intersticial tem sido uma das variáveis mais analisadas nos estudos de sedimentos em zonas estuarinas, uma vez que esta decorre da variação na frequência de inundação pelas águas marinhas, sendo fator condicionante para a distribuição e estrutura das espécies de mangue (TOMLINSOM, 1986).

Considerando que os estudos em estuários hipersalinos, até o presente momento procuram trabalhar aspectos que condicionam as variações da salinidade nos canais estuarinos, assim como da estrutura dos bosques de mangue, este trabalho propõe discutir os efeitos da salinidade como fator preponderante na edafologia dos solos. Portanto, essa pesquisa objetiva analisar a possível influência das variações espaciais da salinidade intersticial e composição granulométrica dos sedimentos para a distribuição da cobertura vegetal ao longo estuário do Rio Apodi-Mossoró (RN - Brasil).

\section{Área de estudo}

O estuário do Rio Apodi-Mossoró apresenta uma área de aproximadamente 975 km² (Figura 1), e está localizado na microrregião de Mossoró (IBGE, 1992), entre os municípios de Areia Branca, Grossos e Mossoró, sendo uma das principais regiões econômicas do Estado do Rio Grande do Norte. Sob o domínio do clima semiárido, a precipitação média da região é de aproximadamente $700 \mathrm{~mm}$, com valores máximos e mínimos de $1.700 \mathrm{~mm}$ e $145 \mathrm{~mm}$, respectivamente. As chuvas são concentradas entre os meses de fevereiro a maio (NIMER, 1989).

Nessa zona estuarina, as altitudes próximas de $0 \mathrm{~m}$ se estendem aproximadamente 30 km para o interior do continente (MAIA; BEZERRA, 2013). Durante a maior parte do ano, ocorre pequena descarga fluvial, por causa do efeito do déficit hídrico e elevadas taxas de evaporação, tornando-o dominado pelos valores extremos de amplitude de maré (3 metros) (MEDEIROS, 2016). Essas condições facilitam o processo de advecção das águas do mar para o interior do estuário pelas correntes de maré. Por outro lado, além das adversidades climáticas, a interferência da hidrologia estuarina pela construção de barragens, prática comum no semiárido brasileiro, compromete a sustentabilidade ambiental desse ecossistema (PINHEIRO; MORAIS, 2010). 
A porção costeira setentrional do Estado do Rio Grande do Norte pode ser agrupada em três compartimentos de relevo: a Planície de Inundação Flúvio-estuarina, onde estão os Terraços Fluviomarinhos e Estuarinos, as Planícies de Maré e a Praia (Zona de Intermaré) (AMARO, 2004).

As extensas planícies de inundação flúvio-estuarina (zona de supramaré) são formadas por depósitos arenosos a pelíticos comumente colonizado por algas, intercalados com depósitos de canais de maré e de transbordamento. São áreas topograficamente mais elevadas que o manguezal, susceptíveis as altas taxas de evaporação, que promovem a precipitação/acúmulo de sais no sedimento, podendo a temperatura do solo atingir valores acima de $40{ }^{\circ} \mathrm{C}$ (SCHAEFFER-NOVELLI, 2005).

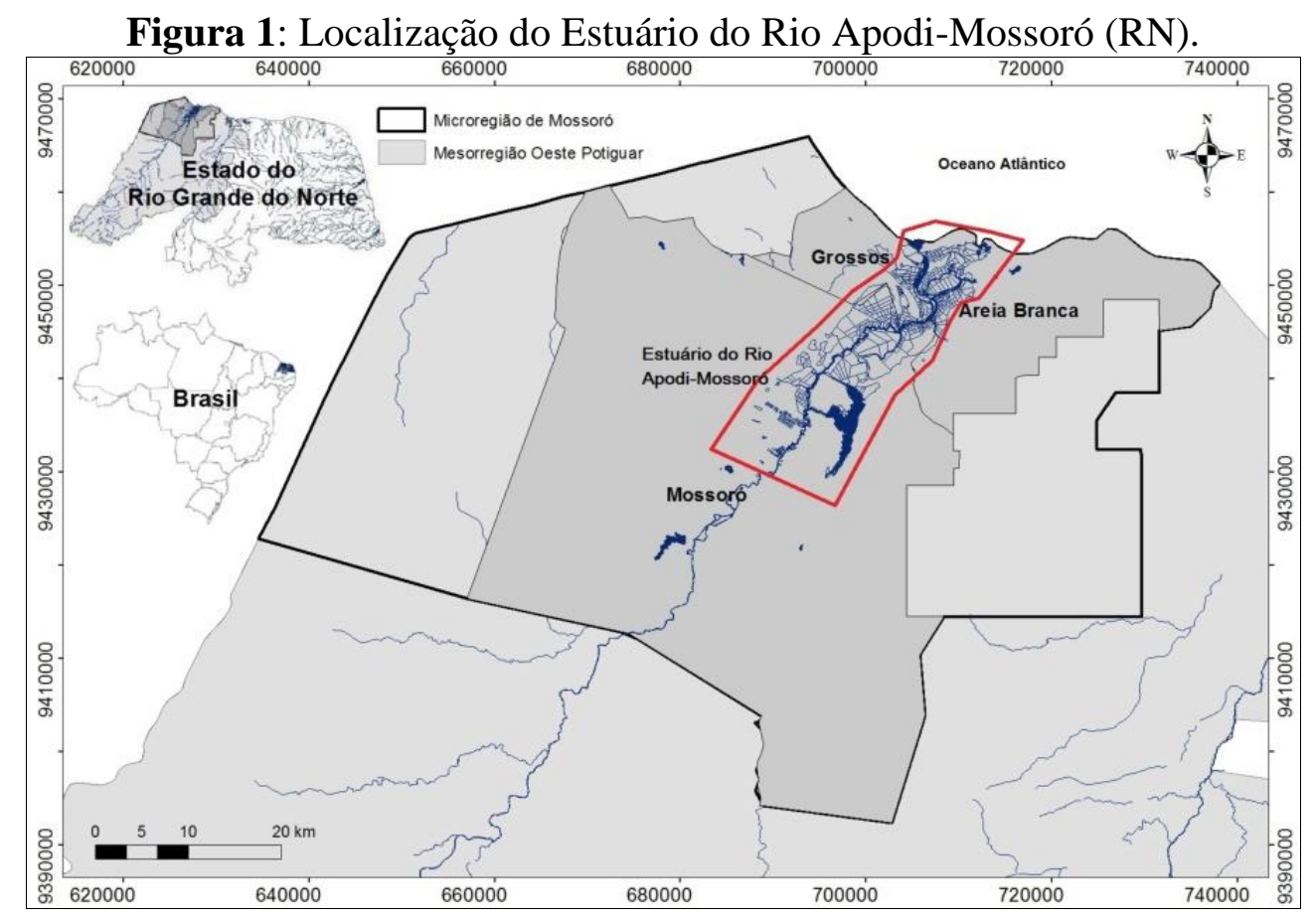

\section{MATERIAIS E MÉTODOS}

\section{Mapeamento da cobertura vegetal}

Foram adquiridas imagens do sensor Landsat-8 OLI/TIRS, através do site da USGS ${ }^{4}$, optando pelo critério de seleção baseado nas cenas de boa qualidade e não comprometidas por cobertura de nuvens na área desejada. Dessa forma, a cena escolhida para esta pesquisa foi a LC82160632014258LGN00, com data de 15 de setembro do ano de 2014.

Inicialmente, as imagens foram submetidas a um processo de reprojeção, sendo adicionado e transformado a sua posição (geometria) para um sistema de coordenadas mais 
adequado. Foi aplicada a transformação de UTM (Universa Transversa de Mercator) com Datum WGS 84 Norte para UTM com Datum de referência indicado para o SIRGAS2000 Zona 24 Sul.

Foram adicionadas as bandas 1 a 7 para a criação de uma única cena multiespectral, com todas as bandas em sequência, de resolução espacial de $30 \mathrm{~m}$ combinadas em uma mesma camada (imagem). Após a geração de uma única imagem multiespectral, essa foi fusionada com a banda 8 (pancromática) para obtenção de um produto com resolução espacial de $15 \mathrm{~m}$. Para fusão dessas imagens foi empregado o método IHS, que corresponde à combinação de três componentes: Saturação (S), Matiz (H) e Intensidade (I) (POLIZEL et al., 2011 apud SILVA, 2015).

A imagem fusionada foi submetida à técnica de segmentação da imagem, que consiste no agrupamento de pixels, segundo um critério de similaridade, definindo regiões homogêneas na imagem (crescimento de regiões). O uso desse recurso facilita o processo de definição automática das formas de vários objetos na imagem (SILVA, 2015). Esse processo foi implementado no sotfware SPRING 5.2, sendo gerada uma shapefile do produto gráfico.

De acordo com o resultado da segmentação, no software ArcGIS 10 (Educational Edition EVA866900120), foi empregado a classificação supervisionada com uso do algoritmo de Máxima Verossimilhança - MAXVER, sendo o processo de classificação realizado através da coleta de várias amostras de treinamento na imagem, referentes às classes pré-definidas (águas, apicuns/salgados e manguezais).

Por último, realizou-se recorte da área de estudo que foi ajustado ao sistema de projeção UTM, Datum SIRGAS-2000 Zona 24 sul. As imagens foram submetidas ao processo de recorte para o enquadramento da área de estudo, através do uso da ferramenta CLIP (Cortar) do ArcGis.

\section{Composição granulométrica e salinidade intersticial dos sedimentos}

Com base na definição espacial das classes, foram selecionados 4 pontos de coleta de sedimentos em trechos de inundação. Também foram definidos 6 pontos de coleta, de acordo com a estratificação longitudinal de salinidade no canal principal identificada nos trabalhos de Medeiros et al. (2014) e Valle-Levinson (2016) (Figura 2).

As coletas de sedimentos foram realizadas com amostrador a uma profundidade de 15 $\mathrm{cm}$, em maré baixa, entre os dias 10 e 11 de setembro/2015. As amostras ficaram acondicionadas em sacos plásticos, previamente identificados e em seguida transportados para 
análise laboratorial. A água intersticial foi obtida in situ a partir da compactação do solo, sendo a salinidade da água intersticial obtida em cada subamostra por meio de um refratômetro digital, com escala entre 0 a 100\%.

A composição textural e granulometria das amostras de sedimentos foram analisadas pelo método gravimétrico descrito por Suguio (1973). As amostras foram analisadas no Laboratório de Geologia e Geomorfologia Costeira e Oceânica da Universidade Estadual do Ceará. As análises estatísticas dos parâmetos foram obtidas pelo programa SAG - Sistema de Análise Granulométrica (Laboratório de Geologia Marinha da Universidade Federal Fluminense, 2000; DIAS; FERRAZ, 2004). A classificação utilizada nos sedimentos foi de Folk e Ward (1957) apud Suguio (1973).

Figura 2: Localização com os pontos de coleta alocados.

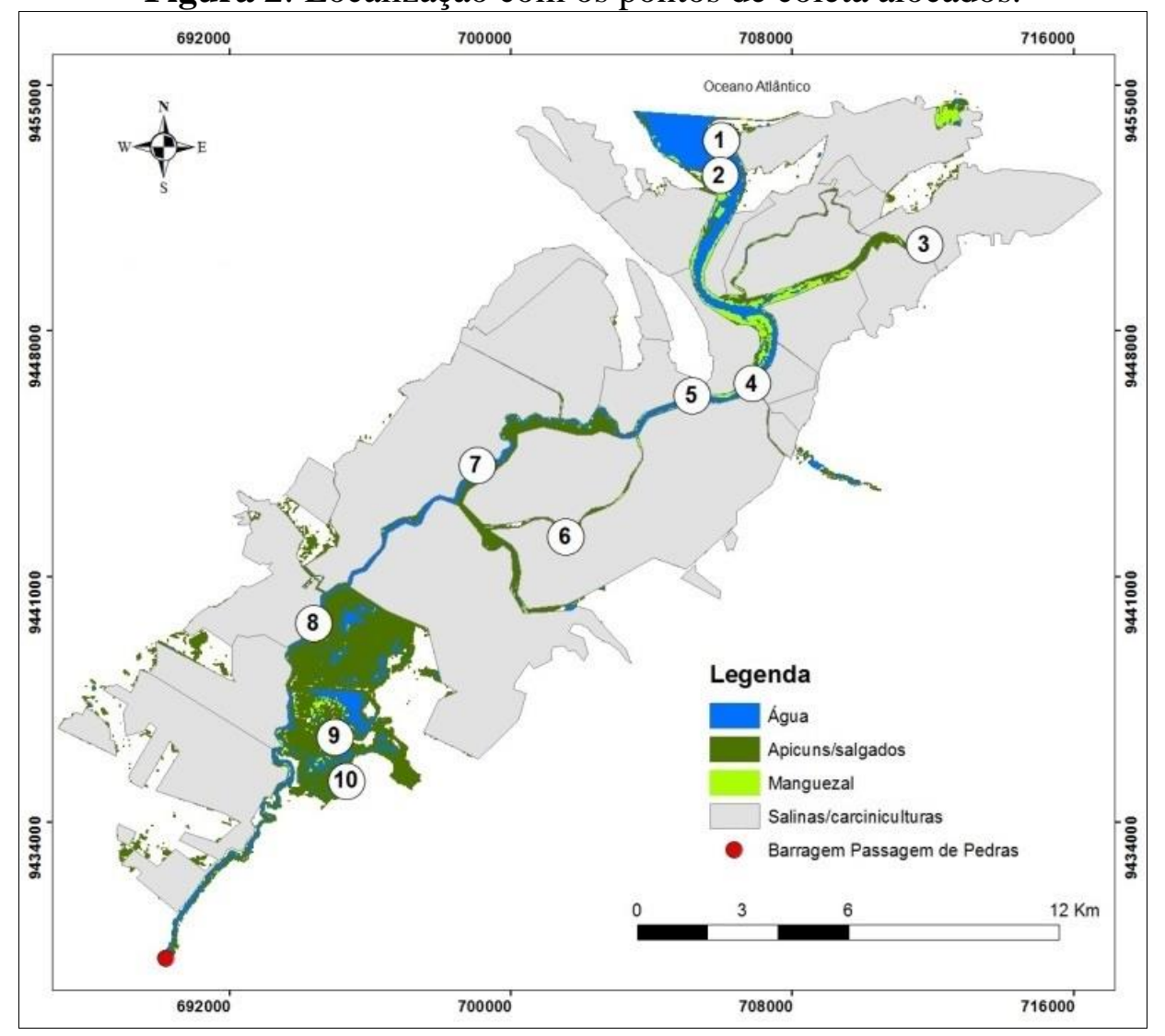

\section{RESULTADOS}

No canal principal, desde a foz até o ponto 5 , a salinidade intersticial é de $50 \%$. São encontradas as mais extensas áreas de manguezal nesse estuário, com trechos superiores a 100 metros de largura, sob domínio de suas vegetações típicas (Figura 3).

Nos pontos 1 e 2, predominam as areias quartzosas de granulometria muito fina com percentuais de $58,4 \%$ e $45,5 \%$, respectivamente (Figura 4). As argilas e siltes correspondem a 
$28,8 \%$ e $25,6 \%$. Não foram registrados cascalhos para ambas as estações. Nesses pontos predominam as fácies de textura areno-argilosas e areno-lamosas.

No ponto 4 , foi encontrado o maior percentual de cascalho $(3,77 \%)$ que associado aos finos $(75,3 \%)$ e ao percentual de areia $(20,9 \%)$, repercutem na textura de lama-arenosa encontrada. Do mesmo modo, o ponto 5, está representado por $85,3 \%$ de finos, $14,4 \%$ de areia e $0,3 \%$ de cascalho.

Figura 3: Distribuição da cobertura vegetal entre a foz e o ponto 5.

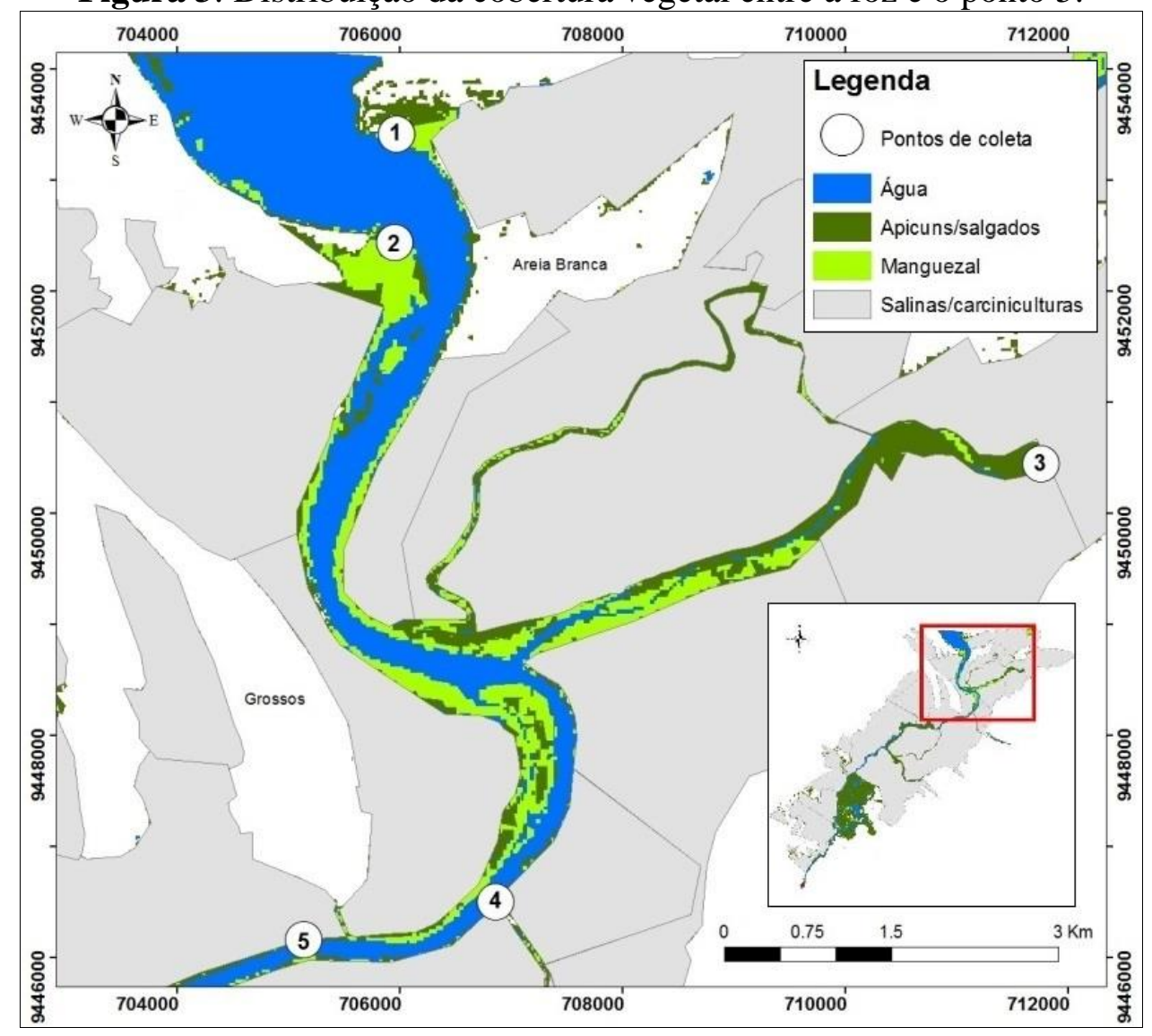


Figura 4: Histograma da variação da composição das frações de sedimentos ao longo da zona estuarina do Rio Apodi-Mossoró (RN).

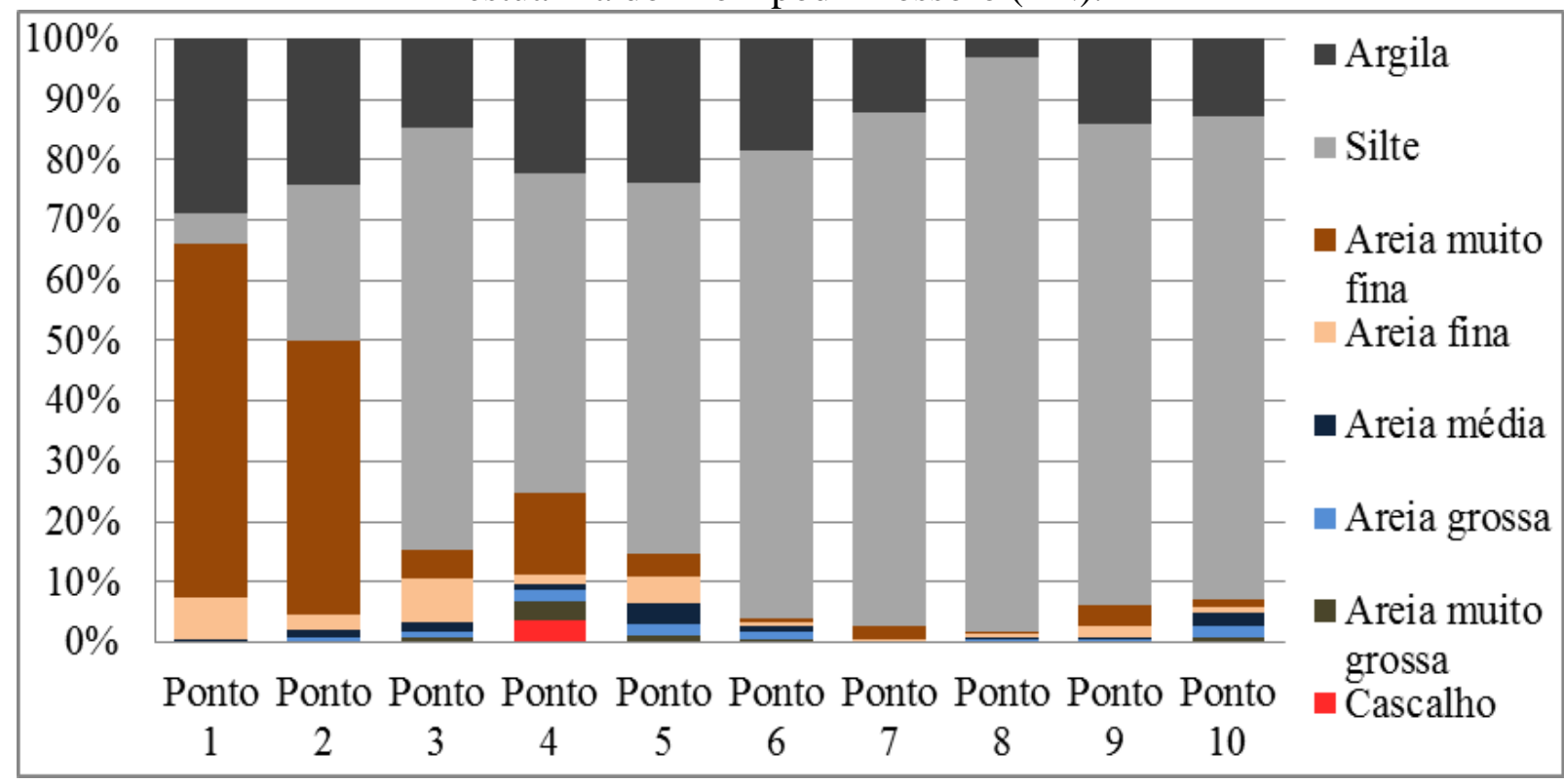

No ponto 3 foi registrado nível de salinidade $>100$ \%; verificou-se a predominância de sedimentos síltico-arenosos, com aproximadamente $84,5 \%$ de finos $(69,8 \%$ de silte e $14,7 \%$ de argila) e 15,39\% de grossos (15,3\% de areia e 0,09\% de cascalho). As frações de silte $(77,5 \%)$ e argila $(18,5 \%)$ totalizaram $96 \%$ dos sedimentos coletados no ponto 6, enquanto que os sedimentos arenosos apresentaram 3,9\% e $0,1 \%$ de cascalho, sendo dominado pelas condições hipersalinas (> $100 \%$ ). Para o ponto 7, a salinidade apresentou 90 $\%$, com percentuais de silte $(85,4 \%)$ e argila (12\%), ambos representando $97,4 \%$, sendo 2,6\% de sedimentos arenosos e ausência de registros de cascalho. No ponto 8 (com salinidade 94 $\%$ ), foi encontrado o maior percentual de silte dentre todos os pontos amostrais, totalizando $95,1 \%$, seguido das frações argila, com $3 \%$, de areia, $1,8 \%$, e de cascalho, $0,1 \%$. No ponto 9 , as frações de silte e argila totalizaram $93,9 \%$, e o restante se refere às frações arenosas, $6 \%$, e cascalho, 0,09\%, sendo que a salinidade neste ponto é de $80 \%$. No ponto 10, silte e argila representaram 92,9\%, com $6,8 \%$ de fração arenosa e $0,17 \%$ de cascalho, enquanto a salinidade é superior a $100 \%$. Entre esses pontos, ocorre o predomínio de apicuns/salgados, em detrimento ao baixo desenvolvimento do manguezal (Figura 5). 
Figura 5: Distribuição da cobertura vegetal no estuário acima do ponto 5.

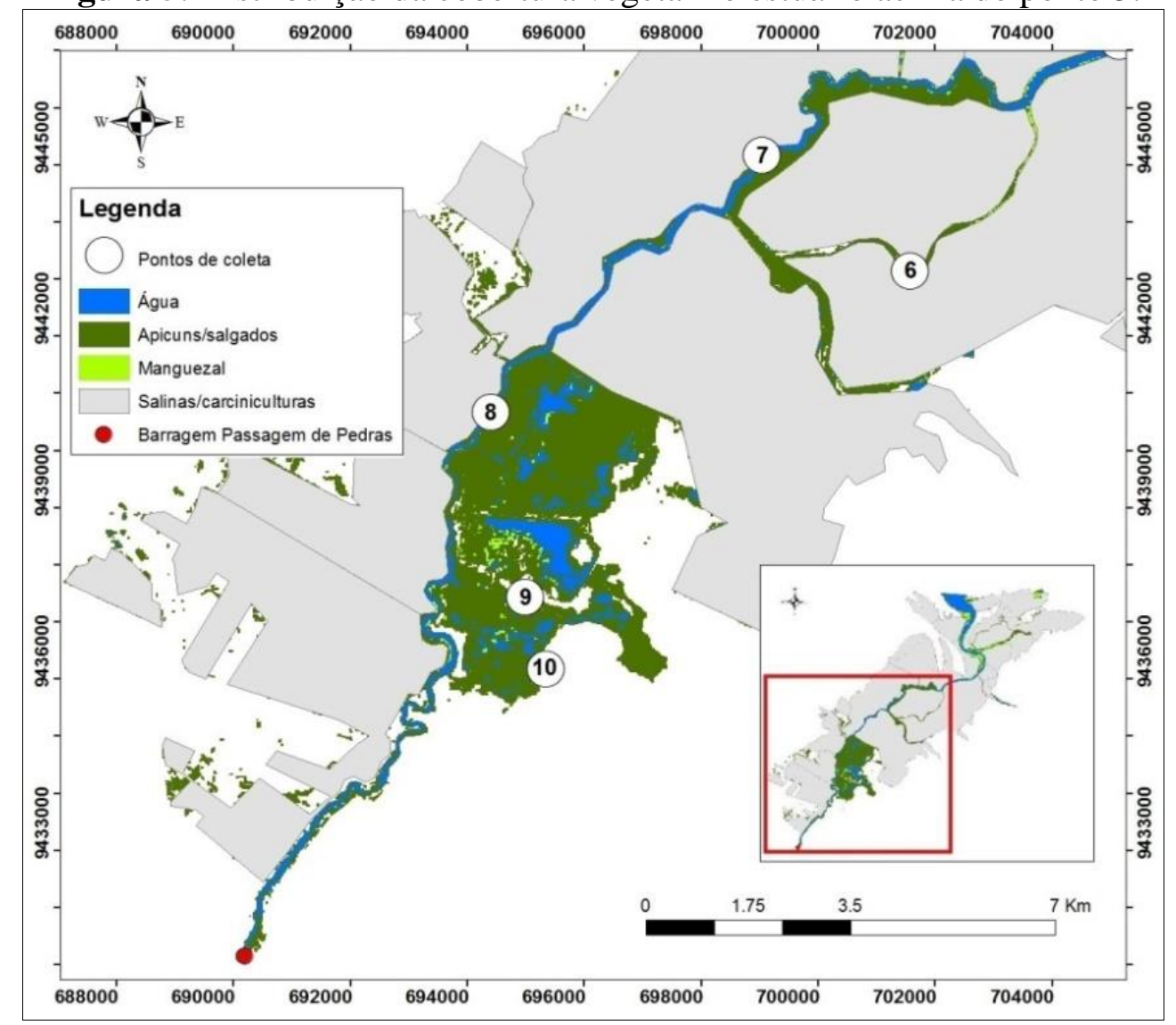

Em relação ao aspecto textural dos sedimentos (Tabela 1), cabe destacar os pontos amostrais 4 e 5 junto ao canal principal, e o ponto 10 na planície de inundação, cujos testemunhos de amostragem eram constituídos por lama arenosa com presença de cascalhos esparsos, o que pode indicar provável consequência da atuação processos erosivos atuantes em áreas adjacentes.

Tabela 1: Classificação textural de Folk - Pontos 3, 4, 5, 6, 7, 8, 9 e 10.

\begin{tabular}{cccc}
\hline Ponto 3 & Ponto 4 & Ponto 5 & Ponto 6 \\
\hline Silte arenoso & $\begin{array}{c}\text { Lama arenosa com } \\
\text { cascalho esparso }\end{array}$ & $\begin{array}{c}\text { Lama arenosa com } \\
\text { cascalho esparso }\end{array}$ & $\begin{array}{c}\text { Silte } \\
\text { Moderamente }\end{array}$ \\
$\begin{array}{c}\text { Pobremente } \\
\text { selecionada }\end{array}$ & $\begin{array}{c}\text { Pobremente } \\
\text { selecionada }\end{array}$ & $\begin{array}{c}\text { Pobremente } \\
\text { selecionada }\end{array}$ \\
$\begin{array}{c}\text { Extremamente } \\
\text { leptocurtica }\end{array}$ & Leptocurtica & Platicurtica & Muito leptocurtica
\end{tabular}




\begin{tabular}{|c|c|c|c|}
\hline $\begin{array}{c}\text { Aproximadamente } \\
\text { simétrica }\end{array}$ & $\begin{array}{c}\text { Aproximadamente } \\
\text { simétrica }\end{array}$ & Assimetria positiva & $\begin{array}{c}\text { Assimetrica muito } \\
\text { positiva }\end{array}$ \\
\hline Ponto 7 & Ponto 8 & Ponto 9 & Ponto 10 \\
\hline Silte & $\begin{array}{c}\text { Lama com cascalho } \\
\text { esparso }\end{array}$ & Silte & $\begin{array}{c}\text { Lama com cascalho } \\
\text { esparso }\end{array}$ \\
\hline $\begin{array}{l}\text { Pobremente } \\
\text { selecionada }\end{array}$ & $\begin{array}{c}\text { Moderadamente } \\
\text { selecionada }\end{array}$ & $\begin{array}{l}\text { Pobremente } \\
\text { selecionada }\end{array}$ & $\begin{array}{l}\text { Pobremente } \\
\text { selecionada }\end{array}$ \\
\hline Platicurtica & Muito platicurtica & Mesocurtica & Leptocurtica \\
\hline Assimetria negativa & $\begin{array}{l}\text { Assimetria muito } \\
\text { negativa }\end{array}$ & Assimetrica negativa & $\begin{array}{l}\text { Assimetria muito } \\
\text { negativa }\end{array}$ \\
\hline
\end{tabular}

\section{DISCUSSÕES}

As áreas com maior proporção de ecossistema de manguezais no estuário estão situadas em margens convexas do canal principal, desde a foz até $\sim 12 \mathrm{~km}$ estuário acima. Essas áreas apresentam maior tendência para depósitos dos sedimentos em função da menor velocidade de corrente nas margens (SOUZA FILHO; EL-ROBRINI, 1996; KNIGHTON, 1998; BRIERLEY; FRYIRS, 2005), facilitando a colonização pela vegetação de mangue. Ainda nesse setor, observa-se que a cobertura vegetal é perfeitamente adaptada às concentrações anuais relativamente homogêneas da salinidade das águas (35\%) (MEDEIROS et al., 2014), e que mesmo no período de estiagem das chuvas, a salinidade intersticial nos sedimentos apresentou $50 \%$.

A elevada hipersalinização encontrada nos pontos $3,6,7,8,9$ e 10, torna-se a principal condicionante edafo-sedimentológica para o baixo desenvolvimento do manguezal e domínio de um ambiente de apicuns/salgados, com desenvolvimento pontual de vegetais halófitos, caracterizados por herbáceas (RAMOS E SILVA, 2004), apresentando trechos com gretas de contração (Figura 6). O perfil da cobertura vegetal ao longo da zona estuarina está relacionado ao efeito inibidor da alta salinidade nos processos fisiológicos do mangue, pelas dificuldades de absorção de água, toxicidade de íons específicos e efeito osmótico do vegetal para a água (GHEYI, et al. 2010). 
Figura 6: Vista parcial do domínio de apicum/salgado no ponto 3, com ocorrência de gretas de contração).

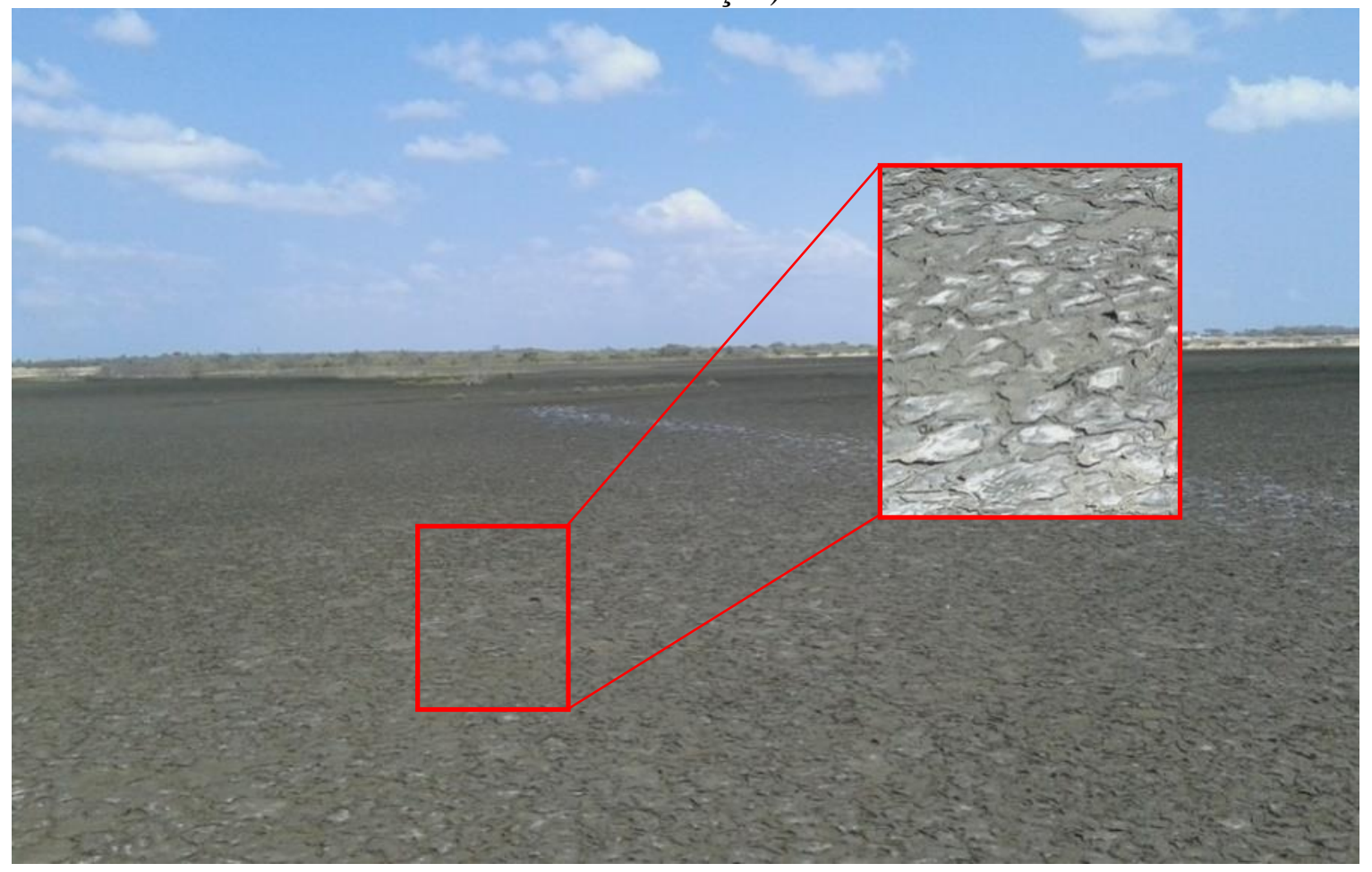

Em razão da ausência de fluxo fluvial contínuo e redução dos processos turbulentos, predomina a sedimentação marinha induzida pela oscilação das marés. A força das marés e a velocidade das correntes tendem a diminuir estuário acima, incluindo em canais secundários, reduzidas também pelas raízes profundas dos mangues, que apresentam maior proporção até o ponto 5 no canal estuarino principal. A conjuntura desses fatores favorece a intensa deposição de sedimentos com granulação fina para toda a zona estuarina, de natureza autóctone ou alóctone (MEDEIROS, 2016).

Todavia, algumas amostras apresentaram seleção intercalada com os materiais mais grossos. Essa afirmação é baseada na assimetria, uma vez que a distribuição longitudinal dos sedimentos revela valores variando entre muito positiva, que está relacionada à presença de sedimentos finos, e muito negativa, que testemunha a presença de material grosso (MABESOONE,1983 apud DIAS, 2005). 
Cabe destacar a localização dos pontos 3, 6, 9 e 10, que estão situados em áreas de planície estuarina e/ou canais secundários, inundadas principalmente durante as preamares de sizígia, em intervalos de tempo relativamente curtos, com tendência de deposição finos, que contribui para o maior aprisionamento do sal, corroborado pelos elevados índices de salinidade intersticial do sedimento (> 80\%) (Tabela 2).

Tabela 2: Relação entre cobertura vegetal, salinidade e classificação granulométrica dos sedimentos.

\begin{tabular}{|c|c|c|c|c|}
\hline $\begin{array}{l}\text { Ponto de } \\
\text { coleta }\end{array}$ & $\begin{array}{l}\text { Ponto de coleta } \\
\text { (planície de } \\
\text { inundação) }\end{array}$ & $\begin{array}{c}\text { Ecossistema } \\
\text { predominante (típica } \\
\text { cobertura vegetal) }\end{array}$ & $\begin{array}{c}\text { Salinidade } \\
\text { Intersticial de } \\
\text { sedimentos }(\%)\end{array}$ & $\begin{array}{c}\text { Classificação } \\
\text { textural }\end{array}$ \\
\hline 1 & - & Manguezal & $<50$ & Areia Argilosa \\
\hline 2 & - & Manguezal & $<50$ & Areia Lamosa \\
\hline- & $\begin{array}{c}3 \text { (canal } \\
\text { secundário) }\end{array}$ & $\begin{array}{l}\text { Apicuns/ } \\
\text { salgados }\end{array}$ & $>100$ & Silte arenoso \\
\hline 4 & - & Manguezal & $<50$ & $\begin{array}{c}\text { Lama arenosa com } \\
\text { cascalho esparso }\end{array}$ \\
\hline 5 & - & $\begin{array}{l}\text { Manguezal e } \\
\text { Apicuns/ } \\
\text { salgados }\end{array}$ & $<50$ & $\begin{array}{l}\text { Lama arenosa com } \\
\text { cascalho esparso }\end{array}$ \\
\hline- & $\begin{array}{c}6 \text { (canal } \\
\text { secundário) }\end{array}$ & $\begin{array}{l}\text { Apicuns/ } \\
\text { salgados }\end{array}$ & $>100$ & Silte \\
\hline 7 & - & $\begin{array}{l}\text { Apicuns/ } \\
\text { salgados }\end{array}$ & 90 & Silte \\
\hline 8 & - & $\begin{array}{l}\text { Apicuns/ } \\
\text { salgados }\end{array}$ & 94 & $\begin{array}{c}\text { Lama com } \\
\text { cascalho esparso }\end{array}$ \\
\hline- & 9 & $\begin{array}{l}\text { Apicuns/ } \\
\text { salgados }\end{array}$ & 80 & Silte \\
\hline- & 10 & $\begin{array}{l}\text { Apicuns/ } \\
\text { salgados }\end{array}$ & $>100$ & $\begin{array}{c}\text { Lama com } \\
\text { cascalho esparso }\end{array}$ \\
\hline
\end{tabular}

\section{CONCLUSÕES}

A vegetação de mangue apresenta maior domínio em trechos situados mais próximos à foz. São dominados por depósitos de lama-arenosa e lama-argilosa que margeiam o canal estuarino, com níveis de salinidade das águas e dos sedimentos inferiores a 50\%o (pontos 1, 2, 4 e 5). Por outro lado, para os demais pontos, a salinidade torna-se superior a $80 \%$; os sedimentos se tornam mais finos, com texturas que variam de silte a lama, testemunhando menor quantidade de energia refletida no ambiente, uma vez que os sedimentos lamosos 
apresentam maior regularidade e compactação, em relação aos sedimentos grossos, permitindo a diminuição da reflexão da energia incidente na área.

Em canais secundários (pontos 3 e 6) e/ou áreas de inundação periódica (pontos 3, 9 e 10), infere-se a ocorrência de regimes diferenciados de transportes e depósitos de sedimentos. Apresentam baixa energia, com maiores inundações periódicas (preamar de sizígia e/ou períodos de chuvas), de pequena largura e profundidade, sendo caracterizados pelo transbordamento do canal e a deposição dos sedimentos de silte e argila.

Nesse sentido, os depósitos de finos por fluxos mais lentos favorece o aprisionamento de sais, permitindo as características naturais edafo-sedimentológicas nitidamente hipersalinas. A elevada salinidade se torna o principal fator limitante ao desenvolvimento do manguezal, e, por conseguinte, a predominância de apicuns/salgados para a típica cobertura vegetal ou mesmo pela formação de trechos completamente desprovidos de vegetação.

Embora seja evidente que a deficiência do fluxo fluvial, provocada pela intermitência dos rios no semiárido, associado aos altos índices de evaporação se constitui como variáveis influenciadoras na distribuição da salinidade no perfil longitudinal do estuário, é mister considerar que as variáveis ligadas à geometria do canal como largura, profundidade e sinuosidade são fundamentais na distribuição dos sedimentos, e portanto, dos solos os quais se constituem como bases para a sustentação da cobertura vegetal, fortemente influenciadas pelas condições de salinidade.

\section{AGRADECIMENTOS}

Ao Programa de Pós-Graduação em Geografia - ProPGeo/UECE e a Coordenação de Aperfeiçoamento de Pessoal de Nível Superior - CAPES, pela concessão da bolsa de mestrado para o primeiro autor. Ao Programa de Pós-Graduação em Ciências Marinhas Tropicais - PPGCMT/UFC e a CAPES, pela concessão da bolsa de doutorado para o primeiro autor. Ao CNPq pela bolsa de produtividade em pesquisa para terceira autora. Ao Laboratório de Geologia e Geomorfologia Costeira e Oceânica da Universidade Estadual do Ceará pelo suporte na realização das atividades laboratoriais. Ao Instituto de Ciências do Mar (LABOMAR) da Universidade Federal do Ceará pelo apoio logístico nas atividades de campo. As salineiras CIASAL, F. SOUTO, NORSAL, SALINOR, São Camilo e SOCEL pelo acesso às margens do estuário do Rio Apodi-Mossoró pela área interna das respectivas empresas.

\section{REFERENCIAS BIBLIOGRÁFICAS}


AMARO, V.E. (Coord.). Mapas de uso e ocupação do solo e das unidades geoambientais do estuário Galinhos/Guamaré - RN, na escala de 1:10.000, baseado em imagens IKONOS de 2000 a 2002.In: Instituto de Desenvolvimento Econômico e Meio Ambiente do Rio Grande do Norte - IDEMA. Zoneamento Ecológico-Econômico dos estuários do litoral norte do Rio Grande do Norte. Natal/RN: FUNPEC/UFRN, 2004. (Relatório Técnico).

BRIERLEY, G.J.; FRYIRS, K.A. Geomorphology and River Management: Applications of the River Styles Framework. Victoria: Blackwell Publishing, 2005.

COSTA, D.F.S.; DE MEDEIROS ROCHA, R.; CESTARO, L.A. Análise fitoecológica e zonação de manguezal em estuário hipersalino. Mercator, v. 13, p. 119-126, 2014.

COSTA, D. F. S.; MEDEIROS, D. H. M.; COSTA, R. S.; ROCHA, R. M. 2015. O sal de ontem e as salinas de hoje - análise da produção de sal marinho no Rio Grande do Norte. In: ALBANO, G.P.; ALVES, L.S.F.; ALVES, A.M. (Org.). Capítulos de Geografia do Rio Grande Norte. Imprensa Oficial do Rio Grande do Norte e CCHLA-UFRN, Natal/RN, v. 2, p. 55-91, 2015.

DIAS, C.B. Dinâmica do sistema estuarino Timonha/Ubatuba (Ceará - Brasil): condições ambientais. 2005. Dissertação (Mestrado em Ciências Marinhas Tropicais) - Programa de Pós-Graduação em Ciências Marinhas Tropicais da Universidade Federal do Ceará, Fortaleza, 2005.

DIAS, G. T. M.; FERRAZ, C. B. SAG - Sistema de Análise Granulométrica. Manual do Usuário. Publicação interna do Departamento de Geologia-LAGEMAR/UFF, 1998. Disponível em: <http:// www.igeo.uff.br>.

FOLK, R.L. Practical Petrographic Classification of Limestones. Bulletin American Association Petroleum Geologists, v. 43, p. 1 - 38, 1959.

IBGE - Instituto Brasileiro de Geografia e Estatística. Censo demográfico 1991: resultados preliminares. Rio de Janeiro, 1992.

IBGE - Instituto Brasileiro de Geografia e Estatística. Mapa do semiárido brasileiro. Rio de Janeiro, 2007.

KNIGHTON, D. Fluvial Forms and Processes: a new perspective. London, 1998.

LAGEMAR/UFF - Laboratório de Geologia Marinha da Universidade Federal Fluminense. SAG - Sistema de Análise Granulométrica. Programa de Análise Completa. Rio de Janeiro, 2000.

MAIA, R.P.; BEZERRA, F.H.R. Tectônica pós-miocênica e controle estrutural de drenagem no Rio Apodi-Mossoró, Nordeste do Brasil. Boletim de Geografia de Maringá, v. 31, p. 5768, 2013.

MARGALEF, R. Limnología. Barcelona: Omega, 1983.

MEDEIROS, D.H.M.; CAVALCANTE; A.A.; COSTA, D.F.S.; DE MEDEIROS ROCHA, R. 2014. Análise da variação espacial e temporal da salinidade no estuário do Rio ApodiMossoró (RN). In: VI Congresso Brasileiro de Oceanografia, 2014, Itajaí. Anais... Itajaí: Universidade do Vale do Itajaí, p. 1183 - 1184.

MEDEIROS, D.H.M. Ambientes hipersalinos no litoral semiárido brasileiro: zona estuarina do Rio Apodi - Mossoró (RN). Dissertação (Mestrado em Geografia) - Programa de Pós Graduação em Geografia. Universidade Estadual do Ceará, Fortaleza, 2016.

MENDES, A.M.S.; FONTES, R.L.F.; OLIVEIRA, M. Variabilidade espacial da textura de dois solos do Campo Salino, no Estado do Rio Grande do Norte. Rev. Ciên. Agron., Fortaleza, v. 39, n. 1, p. 19-27, 2008.

MIRANDA, L.B.; CASTRO, B. M.; KJERFVE, B.Princípios de oceanografia física de estuários. 2. ed. São Paulo: Editora da Universidade de São Paulo, 2012.

MORAIS, J.O.; PINHEIRO, L.S. Rochas e Minerais Industriais do Mar e em Zonas Costeiras. In: Vidal, F.W.H.; Branco, F.A.C.; Souza, J.F.; Matos, I.C.; Roberto, F.A.C. (Org.). Rochas e Minerais Industriais do Estado do Ceará. Realce, Fortaleza/CE, v. 1, p. 148-161, 2005.

NIMER, E. Climatologia do Brasil. 2. ed. Rio de Janeiro: IBGE, 1989. 
PINHEIRO, L. S.; MORAIS, J.O. Interferências de barramentos no regime hidrológico do Estuário do Rio Catú - Ceará - Nordeste do Brasil. Sociedade \& Natureza, Uberlândia, v. 22, n. 2, p. 237-250, 2010.

RAMOS E SILVA, C.A.R. (Org.). Caracterização física, físico-química e química dos estuários Apodi, Conchas, Cavalos, Açu, Guamaré, Galinhos, Ceará-Mirim, Potengi, Papeba e Guaraíra. Natal/RN: Instituto de Desenvolvimento Econômico e Meio Ambiente do Rio Grande do Norte/IDEMA, 2004 (Relatório final).

SANTOS, C. A.; SOBREIRA, F.G. Análise morfométrica como subsídio ao zoneamento territorial: o caso das bacias do Córrego Carioca, Córrego do Bação e Ribeirão Carioca na região do Alto do Rio das Velhas - MG. Revista Escola de Minas, v. 61, p. 77-85, 2008.

SCHAEFFER-NOVELLI, Y.; CINTRÔN-MOLERO, G.; SOARES, M.L.G.; DE-ROSA, T. Brazilian mangroves. Aquatic Ecosystem Health and Management, v. 3, p. 561-570, 2000. SCHAEFFER-NOVELLI, Y. Grupo de ecossistemas: manguezal, marisma e apicum principais vetores de pressão e as perspectivas para sua conservação e usos sustentáveis. Brasília/DF: IBAMA, 2005.

SILVA, A. A. Classificação orientada a objeto para mapeamento da cobertura vegetal da zona urbana de Mossoró/RN. 2015. Dissertação (Mestrado em Ciências Naturais) Programa de Pós Graduação em Ciências Naturais, Universidade Estadual do Rio Grande do Norte, Mossoró, 2015.

SOUZA FILHO, P.W.M.; EL-ROBRINI, M. Morfologia, processos de sedimentação e litofáceis dos ambientes morfo-sedimentares da planície costeira Bragantina, Nordeste do Pará, Brasil. Geonomos, v. 4, n.2, p. 1-16, 1996.

SUGUIO, K. Introdução à Sedimentologia. São Paulo: Edgard Blucher, 1973.

TOMLINSON, P.B. The botany of mangroves. Cambridge: Cambridge University Press, 1986.

VALLE-LEVINSON, A.; SCHETTINI, C. A. Fortnightly switching of residual flow drivers in a tropical semiarid estuary. Estuarine, Coastal and Shelf Science, v. 169, p. 46-55, 2016. 